\title{
The Effect of Degassing on Morphology and Space charge
}

\author{
Y.L. Chong*, G. Chen and Y. F. F. Ho, \\ Department of Electronics \& Computer Science \\ University of Southampton \\ Highfield, Southampton SO17 1BJ \\ United Kingdom \\ *E-mail:ylc@soton.ac.uk
}

\begin{abstract}
It is believed that space charge buildup in cross-linked polyethylene (XLPE) insulation is one of the main cause for premature failure of underground power cables. The space charge activities in XLPE depend on many factors such as additives, material treatment, ambient temperature, insulator/electrode interface, etc. Degassing is one of the material treatment processes commonly employed in cable manufacturing to improve insulation performance. In this paper, investigation on the effect of degassing period on the morphology and space charge was carried out. Planar XLPE samples of the same composite were subjected to different degassing time. It is discovered that apart from removing volatile by-products, degassing also anneals XLPE material; changing the morphology as a result.
\end{abstract}

\section{INTRODUCTION}

Polyethylene (PE) based materials are replacing oil/paper as the main insulating medium for underground high voltage power cables. The main advantage of polyethylene lies in its high intrinsic electrical breakdown strength.

PE has an upper operational temperature of about $70^{\circ} \mathrm{C}$. This limits its application as an insulating material for underground cables since it is not uncommon for the cables to operate at temperature as high as $90{ }^{\circ} \mathrm{C}$. This problem can be largely overcome by cross-linking PE to form cross-linked polyethylene (XLPE).

Cross-linking is the process whereby the polymer structure is modified through the formation of chemical bonds between the polymer chains. The most common method of chemical cross-linking is to trigger a thermally activated catalyst, such as dicumyl peroxide, by subjecting the polymer to high temperatures.

The thermal and mechanical properties of the polymer were reported to be significantly enhanced by the cross-linking process [1]. However, the additives and by-products of the cross-linking reaction can act as impurities and significantly affect the electrical properties of the insulation. One of such effects is the formation of space charge.

\section{CROSS-LINKED POLYETHYLENE}

As mentioned earlier, the main advantages of XLPE is its good electrical, mechanical and thermal properties. However, when subjected to high electric stress over prolong period, charges may be trapped in the material. This is known as space charge.

Space charge formations result in local enhancement of electric stress which in turn alters the internal electric field distribution from the anticipated value. This may lead to breakdown of the insulation at stress level below the designated values. Indeed, stress enhancement level as high as 3 times the applied electric stress has been reported for polyethylene based materials [2].

XLPE may have good thermal performance but along with it comes the problem associated with the residual crossed-linked by-products. Under high electric stress, they can be dissociated into ionic pairs, forming heterocharge at the semi-con/insulator interfaces which enhance the electric stress. This is a main cause for concern since majority of electric breakdown in cables occurs at the interfaces. There are also reports that the cross-linking could act as localized charge trapping centres [1].

One of the most common material treatments adopted by cable manufacturer to improve the performance of cable is degassing. Degassing is the process of subjecting the XLPE to moderately high temperature thereby removing volatile residual by-products.

In this paper, the effect of degassing on space charge and morphology is investigated. The implication of the various degassing parameters on the morphology of the material and their influence on space charge is also explained.

\section{SAMPLE DETAILS}

All samples used in the study was made using cable grade cross-linked polyethylene (Borealis XL4201S) with semi-con electrodes made from the same grade of polyethylene material, but loaded with carbon black to 
increase its conductivity (Borealis LEO592). Both the front and the rear electrodes were hot pressed into the plaque sample about $200{ }^{\circ} \mathrm{C}$ for 10 minutes to ensure cross-linking [3]. All degassing treatments were done in a vacuum oven, after which the samples were cooled at room temperature for 15 minutes. Details of the samples are shown in Table1.

\begin{tabular}{l|l|l|l|l}
\hline & $\begin{array}{l}\text { Thickness } \\
\mathrm{mm}\end{array}$ & $\begin{array}{l}\text { Degassing } \\
\text { Temp. }\end{array}$ & $\begin{array}{l}\text { Degassed } \\
\text { period }\end{array}$ & $\begin{array}{l}\text { Applied } \\
\text { Stress } \\
\mathrm{kV}_{\mathrm{dc}} / \mathrm{mm}\end{array}$ \\
\hline A 3.40 & - & 0 hour & 33.33 \\
B & 3.40 & $60{ }^{\circ} \mathrm{C}$ & 6 hours & 34.15 \\
C & 3.40 & $60{ }^{\circ} \mathrm{C}$ & 12 hours & 34.48 \\
D & 3.40 & $60{ }^{\circ} \mathrm{C}$ & 24 hours & 34.48 \\
E & 3.40 & $60{ }^{\circ} \mathrm{C}$ & 48 hours & 34.90 \\
F & 3.40 & $90{ }^{\circ} \mathrm{C}$ & 48 hours & 30.09 \\
G & 1.60 & $90{ }^{\circ} \mathrm{C}$ & 48 hours & 30.81 \\
\multicolumn{4}{c}{ Table 1. Sample details }
\end{tabular}

\section{EXPERIMENT}

The effect of degassing time and temperature on the morphological structure was examined by the differential scanning calorimetry (DSC). DSC is a tool commonly used for thermal analysis of polymeric-based material. The instrument used, Perkin Elmer DSC7, was calibrated using high purity Idium each time it is used. This is required to prevent possible errors as a result of instrumentation errors such as drift. The temperature was held constant at $25^{\circ} \mathrm{C}$ for $1 \mathrm{~min}$ and the melting endotherms were collected at a heating rate of $10{ }^{\circ} \mathrm{C} / \mathrm{min}$.

Next, space charge measurements on the samples were performed using the Laser Induced Pressure Pulse (LIPP) technique. Utilising a short pulse laser to ablate the front semi-con electrode, an acoustic wave is generated acting as a virtual probe sensitive to charge as it transverse through the material. Details and principle behind its operation can be found in numerous literatures [4-5].

\section{RESULTS AND DISCUSSION}

\section{Weight loss}

Figure 1 shows the normalised weight of samples of different thickness subjected to different degassing temperatures to degassing durations.

It can be seen that both degassing temperature and sample thickness directly effects the amount of volatile by-products that can be removed. Broadly speaking, it is more difficult to remove volatile additives and by-products in thicker samples. This is evident by comparing line 2 with line 3 . It is worth pointing out that the weights of both $3.4 \mathrm{~mm}$ thick samples (line $1 \&$ 2) continue to reduce even after 48 hours of degassing. It is perhaps safe to assume most of the by-products that are remaining are located in the middle of the bulk since it is farthest from surfaces.

The weight of the $1.6 \mathrm{~mm}$ thick sample (line3) stabilises after about 6 hours when degassed at $90{ }^{\circ} \mathrm{C}$, suggesting that the most of the volatile by-products has already been removed. Comparing with line 2 and 3, it can be seen that more by-products is removed in the thinner sample.

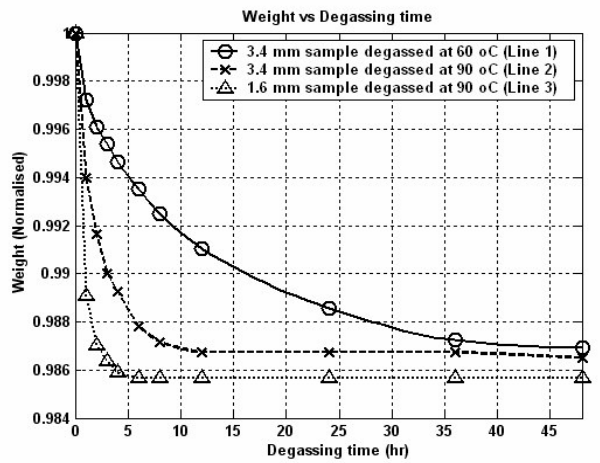

Figure 1: Weight to degassing duration ratio of different samples thickness and degassing temperature

\section{DSC results}

From the previous section, it is obvious that subjecting the samples to moderate heat removes volatile by-products from the samples. What is less apparent, however, is that the morphology of the sample structure may also be modified as a result of degassing.

Figure 2 compares the DSC melting behaviour of five $3.4 \mathrm{~mm}$ thick samples. All samples were degassed at $60{ }^{\circ} \mathrm{C}$ for the duration indicated, with 0 hour representing undegassed sample (sample A).

Apart from sample A, which is dominated by the quenched polymer, the other 4 samples exhibit transition, i.e. a broad feature at low temperature, a smaller peak extending from $73{ }^{\circ} \mathrm{C}$ to $78{ }^{\circ} \mathrm{C}$ and a major peak at about $103{ }^{\circ} \mathrm{C}$.

It was observed that the temperature at which the smaller peak occurs tends to increase with length of degassing. This is because the longer the degassing duration, the time for crystallization also increases.

The addition of the smaller peak suggests that another population of crystal is formed and it becomes more perfect with degassing duration. We can, therefore conclude that annealing of the samples has occurred.

Figure 3 shows the DSC melting behaviour of samples $\mathrm{F}$ and G. They are samples degassed at $90{ }^{\circ} \mathrm{C}$. Similar to samples B to E, the DSC scan of samples F 
and $\mathrm{G}$ also exhibits 2 transitions. However, the smaller peak occurs at a higher temperature of about 91 and $87{ }^{\circ} \mathrm{C}$ respectively. The temperature at which the major peak occurs also shifted to about 106 and $105{ }^{\circ} \mathrm{C}$ respectively. This is because increasing the degassing temperature also increases the crystallization temperature.

These higher transition temperatures suggest that the crystals formed within samples $F$ and $G$ are of higher quality as a higher quality crystal generally has a higher melting temperature.

In conclusion, the length and temperature of which degassing is carried out has a direct effect on the morphology of the XLPE material.

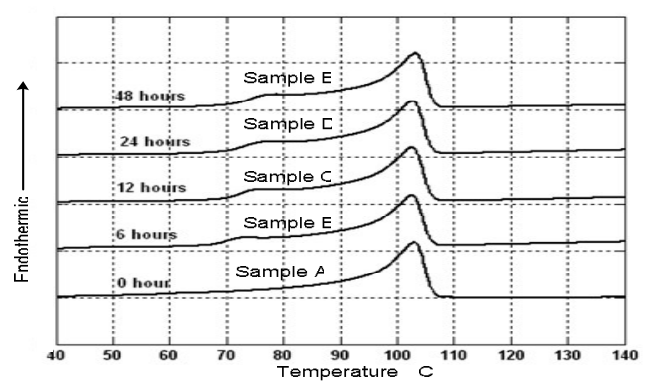

Figure 2: DSC melting traces of $3.4 \mathrm{~mm}$ thick samples degassed at $60{ }^{\circ} \mathrm{C}$ for different duration

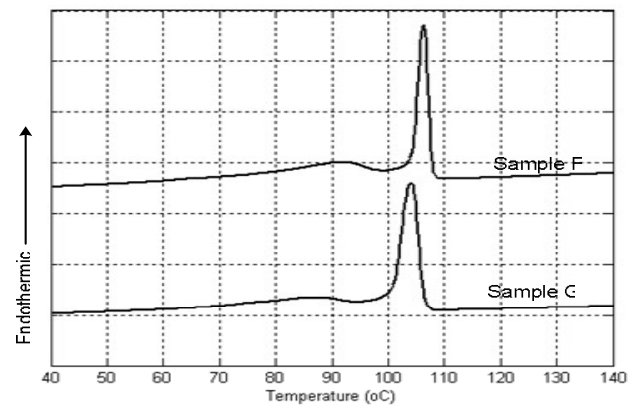

Figure 3: DSC melting traces of sample F \& G

\section{Space charge results}

All the samples were electrically aged for 24 hours and space charge measurements were taken at various interval. According to findings in [2], samples A to E indicate heterocharge at both electrodes throughout the stressing period. This suggests that ionic dissociation and not charge injection/extraction is the dominant process.

The ageing results indicate no homocharge formation observed in samples A to E within the 24 hours dc ageing period. With reference to [2], it was suspected that this may be due to a combination effect of the bulk insulation and semi-con material. However, exact reason for this wasn't clear at this time and further investigation is required.
One possible reason for the absence of homocharge in sample A to E may be due to the fact that there are still quite a substantial amount of by-products left in the samples despite degassing at $60{ }^{\circ} \mathrm{C}$ for 48 hours.

One way of removing more by-products from the sample is to increase the degassing temperature. Sample $\mathrm{F}$ is a $3.4 \mathrm{~mm}$ thick sample degassed at $90{ }^{\circ} \mathrm{C}$ for 48 hours. The voltage-off space charge profiles are shown figure 4 .
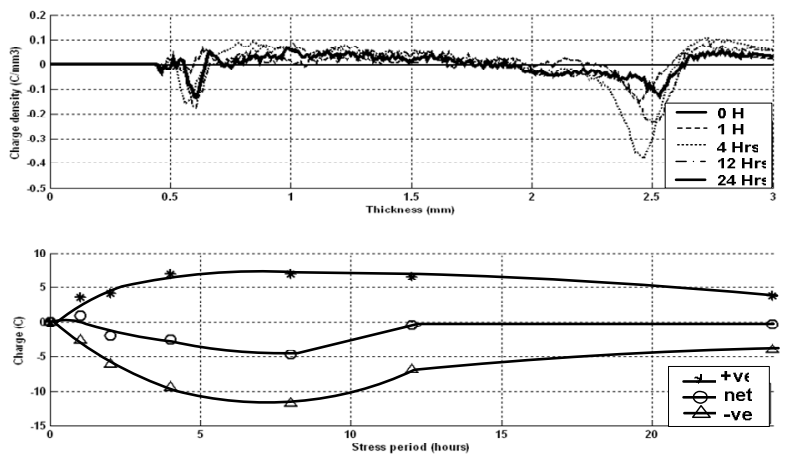

Figure 4: Space charge profiles and charge integration in sample $\mathrm{F}$

The weight loss ratio (line 2 of figure 2) and space charge profiles of sample $\mathrm{F}$ indicate that by degassing the sample at higher temperature, more by-products can be removed, resulting in homocharge formation at the electrodes. In such a case, charge injection/extraction is dominant over ionic dissociation.

It is noted that the amount homocharge at both electrodes decreases after 8 hours of dc ageing. It is probably due to increase in bulk stress as a result of homocharge formation during the first 8 hours. This increase in bulk stress will in turn ionise the by-products that may still remain in the middle of the bulk, which as mentioned earlier is probably the area least susceptible to degassing. The heterocharge produced by ionic dissociation will, therefore, de-trap and cancel off the homocharge at the electrodes.

Even more volatile by-products can be removed from the sample by reducing its thickness. Thinner $(1.6 \mathrm{~mm})$ sample was made using the same type of materials for the XLPE bulk and semi-con electrodes.

The weight loss ratio of sample $\mathrm{G}$ (line 3 ) indicates that more by-products can be removed when a $1.6 \mathrm{~mm}$ thick sample is degassed at $90{ }^{\circ} \mathrm{C}$ for a duration of 48 hours.

Obvious similarities can be seen when comparing the space charge profiles of sample $F$ and sample $G$ (Figure 5). Like sample F, sample $G$ exhibits homocharge at both electrodes. Another noticeable similarity of sample $F$ and $G$ is the net charge is negative throughout, 
in other words, more negative charge is trapped than positive charge. One possible explanation for this is that it is easier to trap negative charge than positive charge. This is evident by looking at the relatively higher rate of increase of negative space charge in each sample before they start to be de-trapped by the positive charge. Other reasons for the negative net charge could be that more negative charge is injected into the samples than positive charge or it could also be the combination of both.

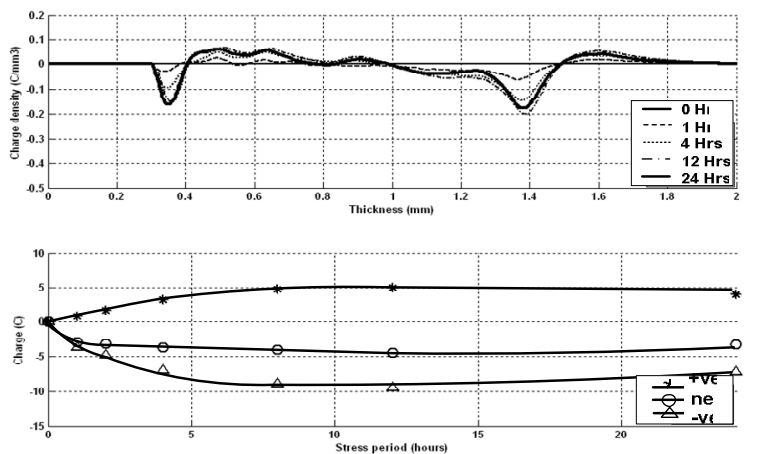

Figure 5. Profiles and charge integration of space charge in sample $\mathrm{G}$.

The main difference of sample $F$ and $G$ is that in the case of the latter, the amount of negative homocharge only starts to decrease after 12 hours of dc ageing. On the other hand, the amount of positive charge very much stabilized after 8 hours of dc ageing.

The decrease in negative homocharge is most probably due to de-trapping by positive charge. The question to address is the origin of the positive charge. One possible source is ionization of by-products in the middle of the bulk. While this may be possible in sample $\mathrm{F}$, it is however believed to have minimal effect in sample $G$ as that its weight loss ratio stabilizes after 6 hours of degassing, suggesting that most of the by-products has been removed.

Another possible source of positive charge may be the migration of charge from the anode to the cathode. It is shown that positive charge is more difficult to trap; therefore, significantly more positive charge injected will not be trapped at the vicinity of the anode but rather attracted to the cathode hence cancel or recombine with the negative charge, as the space charge measurement technique only gives the resultant net charge density profile across the sample.

\section{CONCLUSION}

In this paper, the influence of degassing has on the morphological development and space charge of XLPE smaples was reported. Parameters such as degassing duration, degassing temperature and sample thickness were investigated.

More volatile by-products can be removed by increasing the length and temperature of degassing. It is also proven that it is easier to remove the by-products from thinner samples.

Apart from removing volatile by-products, degassing also has annealing effect on the sample. Likewise, factors that affect the morphological development include degassing duration, temperature and thickness of the sample.

Space charge distribution is highly dependent on the amount of by-products in the samples. Complication of space charge behavior is attributed to ionic dissociation, de-trapping and perhaps difference in morphology of each sample.

\section{ACKNOWLEDGMENT}

The authors would like to thank Dr. Alun Vaughan and Mr. Chris Martin of University of Southampton for provision of the sample material and help with the Perkin Elmer DSC7 respectively.

\section{REFERENCES}

[1] G.A. Cartwright, $\mathrm{PhD}$ thesis, "The measurement of space charge and its effect on the breakdown strength of solid polymeric insulation, 1994, University of Southampton.

[2] Y. F. F. Ho, Y. L. Chong, G. Chen, "Effect of the length of degassing period on the space charge dynamic in XLPE insulation under DC stressing condition", pp. 160-163 (ICMEP 2003)

[3] A.S. Vaughan, Y. Zhao, L.L. Barre, S.J. Sutton , S.G. Swingler "On additives, morphological evolution and dielectric breakdown in low density polyethylene", Eur. Polym. J. 39(2), 2003, pp.355-365

[4] P. Laurenceau, G. Dreyfus and J. Lewiner, "New Principle for the determination of potential distributions in dielectrics", Physical Review Letters, Volume 38, Number 1, 3 January 1977, pp. 46-49.

[5] C. Alquié, T. Ditchi anf J. Lewiner, "Measurement of charge density in insulating material for high voltage cables", Proc. $2^{\text {nd }}$ Conf. on Properties and application of dielectric materials, IEEE, 1988 pp.434-437 